\title{
Wogonin potentiates cisplatin-induced cancer cell apoptosis through accumulation of intracellular reactive oxygen species
}

\author{
FAN HE* ${ }^{*}$ QIONG WANG ${ }^{*}$, XUE-LIAN ZHENG, JIA-QI YAN, LAN YANG, \\ HONG SUN, LI-NA HU, YONG LIN and XIA WANG
}

\begin{abstract}
Laboratory of Molecular and Translational Medicine, Key Laboratory of Obstetric and Gynecologic and
Pediatric Diseases and Birth Defects of Ministry of Education, Department of Gynecology and Obstetrics, West China Second University Hospital, Sichuan University, Chengdu 610041, P.R. China
\end{abstract}

Received January 19, 2012; Accepted March 26, 2012

DOI: $10.3892 / o r .2012 .1841$

\begin{abstract}
Chemoresistance to cisplatin is a major limitation of cisplatin-based chemotherapy in the clinic. The combination of cisplatin with other agents has been recognized as a promising strategy to overcome cisplatin resistance. Previous studies have shown that wogonin (5,7-dihydroxy-8-methoxyflavone), a flavonoid isolated from the root of the medicinal herb Scutellaria baicalensis Georgi, sensitizes cancer cells to chemotheraputics such as etoposide, adriamycin, tumor necrosis factor-related apoptosis-inducing ligand (TRAIL) and TNF. However, the effect of wogonin on cisplatin-induced cytotoxicity has not been previously reported. In this study, the non-small cell lung cancer cell line A549 and the cervical cancer cell line HeLa were treated with wogonin or cisplatin individually or in combination. It was found for the first time that wogonin is able to sensitize cisplatin-induced apoptosis in both A549 cells and HeLa cells as indicated by the potentiation of activation of caspase-3, and cleavage of the caspase- 3 substrate PARP in wogonin and cisplatin co-treated cells. Importantly, wogonin robustly induced $\mathrm{H}_{2} \mathrm{O}_{2}$ accumulation in these cells, which substantially contributes to the sensitization of cisplatin cytotoxicity by wogonin, as two reactive oxygen species scavengers, butylated hydroxyanisole (BHA) and $\mathrm{N}$-acetyl-L-cysteine (NAC), significantly suppressed the potentiated cytotoxicity caused by wogonin and cisplatin co-treatment. The results from this study provide important
\end{abstract}

Correspondence to: Dr Xia Wang and Dr Li-Na Hu, Laboratory of Molecular and Translational Medicine, Key Laboratory of Obstetric and Gynecologic and Pediatric Diseases and Birth Defects of Ministry of Education, Department of Gynecology and Obstetrics, West China Second University Hospital, Sichuan University, Chengdu 610041, P.R. China

E-mail: xiawang@scu.edu.cn

E-mail: cqhulina@126.com

${ }^{*}$ Contributed equally

Key words: cisplatin, wogonin, apoptosis, reactive oxygen species new evidence supporting the potential use of wogonin as a cisplatin sensitizer for cancer therapy.

\section{Introduction}

Cisplatin (cis-diamminedichloroplatinum, DDP) is one of the most potent and widely used chemotherapeutic agents for treatment of a wide variety of solid tumors in clinic. By interacting with DNA to form intra- and inter-strand adducts to disrupt DNA replication and transcription, cisplatin activates several cellular signal pathways including those involving ATR, p53, p73 and MAPK, which results in apoptosis (1). However, cisplatin-induced apoptotic cell death can be attenuated, and chemoresistance to cisplatin is a major limitation of cisplatinbased chemotherapy. The molecular mechanisms responsible for cisplatin resistance appear to be multifactorial. Reduced drug uptake, increased drug inactivation and increased DNA repair would limit the extent of cisplatin-induced DNA damage. Moreover, mechanisms that inhibit propagation of the DNA damage signal to the apoptotic machinery have also been proposed, which include loss of damage recognition, loss of p53 function, overexpression of HER-2/neu, activation of the PI3-K/Akt pathway, overexpression of antiapoptotic Bcl-2, and defects in apoptotic pathways $(2,3)$. Therefore, combination of cisplatin with other agents that could modulate DNA damage and related signal pathways is a promising strategy to overcome cisplatin resistance.

Because they are generally safe to humans, naturally occurring compounds from diets or medicinal plants are good candidates for increasing the cisplatin anticancer activity. Wogonin (5,7-dihydroxy-8-methoxyflavone) is a flavonoid isolated from the root of the medicinal herb Scutellaria baicalensis Georgi, which has been shown to exert antioxidant, anti-inflammatory, antiviral and anticancer activities in vitro as well as in vivo (4-7). Importantly, wogonin showed no significant toxicity to normal peripheral blood T cells (8), and was able to reduce etoposide-induced apoptotic cell death in normal cells such as bone marrow cells and thymocytes (9). Therefore, wogonin is a good potential sensitizer for cisplatin anticancer activity. Wogonin was found to potentiate etoposide-induced apoptosis in cancer cells through inhibition of P-glycoprotein (10), to overcome IL-6-induced adriamycin 
resistance through suppressing IL-6-mediated aldo-keto reductase (AKR) superfamily member dihydrodiol dehydrogenases (AKR1C1/1C2) overexpression in human non-small lung cancer cells (11), and to enhance the cytotoxicity of tumor necrosis factor-related apoptosis-inducing ligand (TRAIL) through upregulating p53 and PUMA (12). Recently, we found that wogonin sensitizes cancer cells to tumor necrosis factor $\alpha$ (TNF- $\alpha$ )-induced apoptosis by blocking TNF-induced $\mathrm{NF}-\kappa \mathrm{B}$ activation (13). However, the effect of wogonin on the anticancer activity of cisplatin, one of the most widely used chemotherapeutics in clinic, has not been investigated. In this study, we treated the non-small cell lung cancer cell line A549 and the cervical cancer cell line HeLa with the combination of wogonin and cisplatin and found for the first time that wogonin potently sensitizes cisplatin-induced cancer cell apoptosis through triggering intracellular reactive oxygen species (ROS) accumulation, which added important new evidence supporting the potential use of wogonin as adjuvant of cisplatin.

\section{Materials and methods}

Reagents. Wogonin was from National Institute of the Control Pharmaceutical and Biological Products (Beijing, China). Cisplatin, butylated hydroxyanisole (BHA) and N-acetylL-cysteine (NAC) were purchased from Sigma (St. Louis, MO). Z-VAD-FMK was from Calbiochem (La Jolla, CA). ROS-sensitive fluorescent dye 5-(and-6)-chloromethyl-2', 7'-dichlorodihydrofluorescein diacetate acetyl ester (CM-H $\left.\mathrm{H}_{2} \mathrm{DCFDA}\right)$ and dihydroethidium (DHE) were purchased from Molecular Probes (Eugene, OR). Antibodies against active caspase-3, poly (ADP-ribose) polymerase (PARP) were from BD Bioscience (San Diego, CA). Anti- $\beta$-actin antibody was from Protein Tech (Chicago, IL).

Cell culture and cell death assay. A549 (a non-small cell lung cancer cell line) and HeLa (a cervical cancer cell line) were from American Type Culture Collection (ATCC, Manassas, VA) and grown in RPMI-1640 supplemented with $10 \%$ fetal bovine serum (Hyclone, Logan, UT), $100 \mathrm{U} / \mathrm{ml}$ penicillin and $100 \mu \mathrm{g} / \mathrm{ml}$ streptomycin. The cultured cells were kept in a $37^{\circ} \mathrm{C}$ humidified incubator with $5 \% \mathrm{CO}_{2}$. For cell death assay, cells were seeded in 96-well plate and after overnight culture were then treated as indicated in each figure legend. Cell death was assessed based on the release of lactate dehydrogenase (LDH) using a cytotoxicity detection kit from Promega (Madison, WI) as described previously (14). All the experiments were repeated 3-5 times and the average is shown in each figure.

Western blot analysis. Cells were treated as indicated in figure legend and cell lysates were prepared by lysing cells with M2 buffer [20 mmol/1 Tris- $\mathrm{HCl}$ ( $\mathrm{pH} 7.6), 0.5 \% \mathrm{NP} 40$, $250 \mathrm{mmol} / 1 \mathrm{NaCl}, 3 \mathrm{mmol} / 1$ EDTA, $3 \mathrm{mmol} / 1$ EGTA, $2 \mathrm{mmol} / 1$ DTT, $0.5 \mathrm{mmol} / 1$ phenylmethylsulfonyl fluoride, $20 \mathrm{mmol} / 1$ $\beta$-glycerophosphate, $1 \mathrm{mmol} / 1$ sodium vanadate and $1 \mu \mathrm{g} / \mathrm{ml}$ leupeptin]. Cell lysates were then subjected to SDS-PAGE and analyzed by western blotting using specific antibodies. The proteins were seen by enhanced chemiluminescence (Millipore, Billerica, MA) using Bio-Rad Image station (Hercules, CA). Each experiment was repeated at least 3 times and representative results are shown.
Apoptosis analysis by flow cytometry. Apoptosis was detected by flow cytometric analysis using an Annexin V-FITC Apoptosis Detection kit (Nanjing KeyGen Biotech, Nanjing, China). Cells were treated as indicated in the figure legend, and then were double stained with Annexin V-FITC and propidium iodide (PI) following manufacturer's instruction. The stained cells were analyzed by flow cytometry (Beckman Coulter, Inc., Brea, CA). Cells that are in early apoptosis are Annexin V-FITC positive and PI negative; and cells that are in late apoptosis or already dead are both FITC Annexin V and PI positive.

Detection of ROS. Cells were seeded in 12-well plates and after overnight culture were then treated as indicated in each figure legend. Thirty minutes before collecting cells, $\mathrm{H}_{2} \mathrm{O}_{2}$-sensitive fluorescent dye CM- $\mathrm{H}_{2}$ DCFDA $(5 \mu \mathrm{M})$ or superoxide-sensitive dye DHE $(5 \mu \mathrm{M})$ was added. ROS were detected by flow cytometry (Beckman Coulter, Inc.) as reported previously (15).

Statistical analysis. All numerical data are expressed as mean \pm standard deviation (SD). Statistical significance was examined by Student's paired-sample t-test using the SPSS statistics software package (IBM SPSS, Chicago, IL) and $\mathrm{P}<0.05$ was used for significance.

\section{Results}

Wogonin enhances cisplatin-induced cell death in cancer cells. Aiming to overcome chemoresistance to cisplatin in cancer cells, we first investigated whether wogonin is able to enhance the anticancer activity of cisplatin. We treated the A549 cells with $10 \mu \mathrm{M}$ of wogonin, $10 \mu \mathrm{M}$ of cisplatin or both for $60 \mathrm{~h}$ and cell death was observed microscopically. As shown in the representative images (Fig. 1A), while cisplatin or wogonin caused limited cell death, co-treatment of these agents resulted in significantly enhanced cytotoxicity. To more quantitatively measure cell death, A549 cells were treated with increasing concentrations of wogonin (5-20 $\mu \mathrm{M})$ and a fixed concentration of cisplatin $(7.5 \mu \mathrm{M})$ and cell death was detected by LDH release assay. The results showed that while cisplatin alone caused about $25 \%$ cell death in A549 cells, wogonin synergistically sensitized A549 cells to cisplatin-induced cell death in a dose-dependent manner (Fig. 1B). The synergism that killed about $80 \%$ of cells was detected at the highest dose of wogonin $(20 \mu \mathrm{M})$, a concentration of wogonin alone that only caused moderate cell death $(\sim 12 \%)$. Conversely, a similar dose-dependent potentiation of cytotoxicity was detected when increasing concentrations of cisplatin with a fixed wogonin dose was used (Fig. 1C). The sensitization of cisplatin's anticancer activity was further validated in the cervical cancer cell line HeLa. A similar dose-dependent synergism either with fixed concentration of wogonin or with fixed concentration of cisplatin was observed (Fig. 1D and E), suggesting wogonin is able to sensitize cancer cells to cisplatin-induced cytotoxicity.

Wogonin enhances cisplatin-induced cancer cell apoptosis. We next investigated whether wogonin potentiates cisplatininduced cell death through enhancing apoptosis. HeLa cells were treated with wogonin, cisplatin alone or both. The cells were stained with Annexin V-FITC and PI, apoptosis was analyzed by flow cytometry. As shown in Fig. 2A, both 

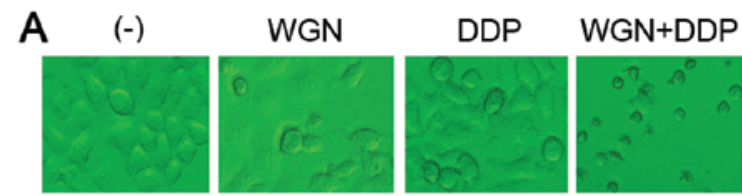

B
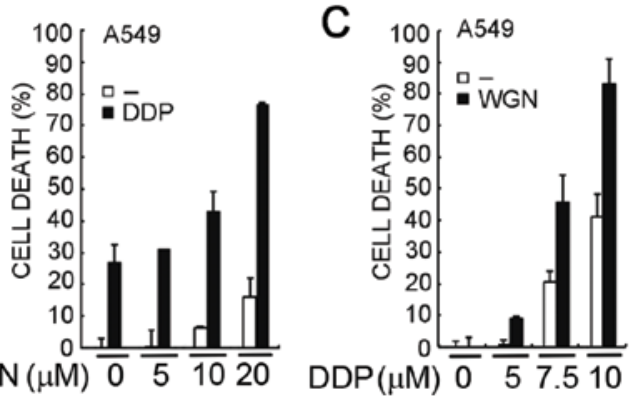

D

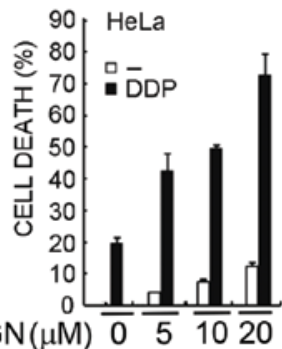

$\mathrm{E}$

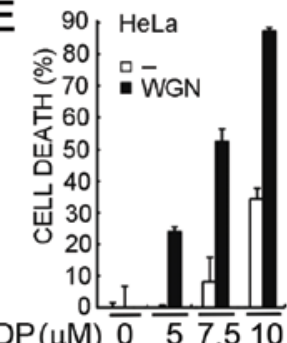

Figure 1. Wogonin sensitizes cancer cells to cisplatin induced cytotoxicity. (A) A549 cells were treated with $10 \mu \mathrm{M}$ wogonin (WGN) or $10 \mu \mathrm{M}$ cisplatin (DDP) or both for $60 \mathrm{~h}$, cell death was observed under microscope and representative pictures are shown. (B) A549 cells were treated with increasing concentrations of wogonin $(5-20 \mu \mathrm{M})$ or fixed concentration of cisplatin $(7.5 \mu \mathrm{M})$ alone or both for $72 \mathrm{~h}$. Cell death was measured by an assay based on the release of lactate dehydrogenase (LDH release assay). Columns, mean of three experiments; bars, SD. (C) A549 cells were treated with fixed concentration of wogonin $(10 \mu \mathrm{M})$ or increasing concentrations of cisplatin $(5-10 \mu \mathrm{M})$ alone or both for $72 \mathrm{~h}$. Cell death was measured as described in (B). (D) and (E) HeLa cells were treated as described in (B) and (C), respectively, and cell death was measured as described in (B).

early apoptotic (Annexin V-FITC positive and PI negative, $3.5 \%$ ) and late apoptotic (both Annexin V-FITC and PI positive, $10.3 \%$ ) cell population were significantly increased in wogonin and cisplatin co-treated cells compared to the samples individually treated with cisplatin $(3.1 \%$ and $4.7 \%)$ or wogonin $(1.9 \%$ and $1.5 \%)$, indicating that the enhanced cell death is mainly through apoptosis. The activation of caspases was also detected by western blotting. Whereas the activation of caspase cascade was barely detected in wogonin or cisplatin alone treated cells, the activation of caspase- 3 and cleavage of the caspase-3 substrate PARP were significantly enhanced in cisplatin and wogonin co-treated A549 cells and HeLa cells (Fig. 2B). The pan-caspase inhibitor Z-VAD-FMK effectively suppressed the synergistic cytotoxicity induced by wogonin and cisplatin co-treatment (Fig. 3), further confirming that the sensitization to cisplatin by wogonin is through enhancement of apoptosis in cancer cells.

Wogonin-induced intracellular $\mathrm{H}_{2} \mathrm{O}_{2}$ accumulation contributes to the synergistic cytotoxicity induced by wogonin plus cisplatin. It has been well established that ROS, a group of reactive oxygen-containing species including superoxide, hydrogen peroxide $\left(\mathrm{H}_{2} \mathrm{O}_{2}\right)$ and hydroxyl radical, are important
A

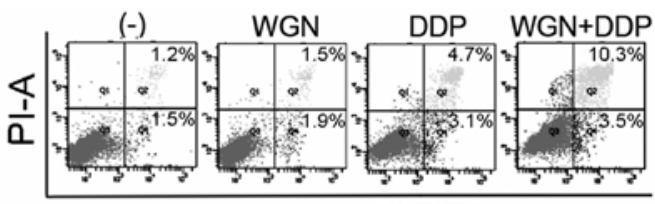

Annexin V-FITC

B

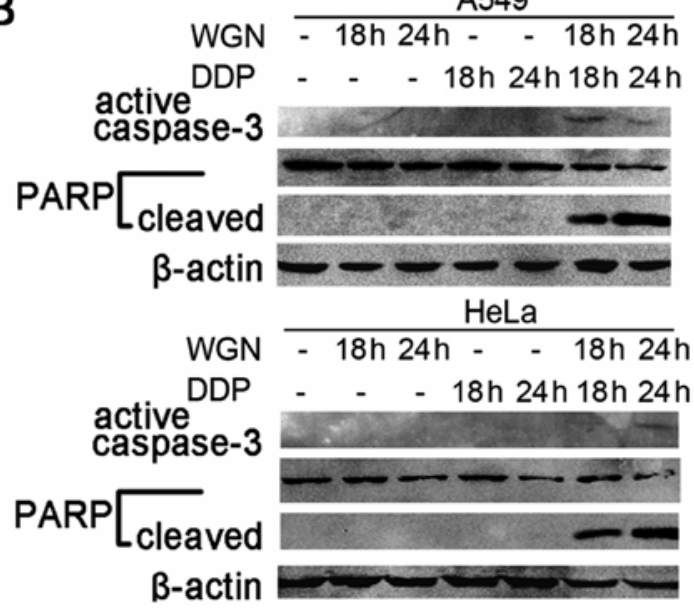

Figure 2. Wogonin enhances cisplatin-induced cancer cell apoptosis (A) HeLa cells were treated with $10 \mu \mathrm{M}$ wogonin or $7.5 \mu \mathrm{M}$ cisplatin or both for $24 \mathrm{~h}$ and then stained with Annexin V and propidium iodide (PI) followed by flow cytometry analysis. Early apoptosis is defined by Annexin $\mathrm{V}^{+} /$ $\mathrm{PI}^{-}$staining $(\mathrm{Q} 4)$ and late apoptosis is defined by Annexin $\mathrm{V}^{+} / \mathrm{PI}^{+}$staining (Q2). (B) A549 cells and HeLa cells were treated with $10 \mu \mathrm{M}$ wogonin or $7.5 \mu \mathrm{M}$ cisplatin individually or both for 18 and $24 \mathrm{~h}$. Active caspase-3 and PARP were detected by western blotting. $\beta$-actin was detected as an input control.

signaling mediators for cell death pathways. Our previous work has demonstrated that wogonin induces intracellular accumulation of $\mathrm{H}_{2} \mathrm{O}_{2}$ in cancer cells, which contributes substantially to the synergistic cytotoxicity induced by wogonin plus TNF (13). The role of ROS in wogonin plus cisplatin-induced synergistic cytotoxicity was thus investigated. Cells were treated with wogonin, cisplatin or both, stained with two ROS-specific dyes, CM- $\mathrm{H}_{2}$ DCFDA that is specific for hydrogen peroxide $\left(\mathrm{H}_{2} \mathrm{O}_{2}\right)$ or DHE that is specific for superoxide, and then analyzed by flow cytometry. As expected, wogonin induced strong intracellular $\mathrm{H}_{2} \mathrm{O}_{2}$ accumulation in both A549 cells and HeLa cells, as indicated by significant rightward shift of the peaks of wogonin treated cells compared with that of the control cells (Fig. 4A). The treatment with wogonin plus cisplatin showed similar trend and even more striking extent of $\mathrm{H}_{2} \mathrm{O}_{2}$ induction as treated by the wogonin alone. On the contrary, wogonin and cisplatin had marginal effect on cellular superoxide level in A549 and HeLa cells (Fig. 4B), which is consistent with our previous results (13). Then, we treated cells with ROS scavengers BHA or NAC to remove $\mathrm{H}_{2} \mathrm{O}_{2}$. As shown in Fig. 5A, these two scavengers effectively suppressed the synergistic cytotoxicity induced by wogonin and cisplatin co-treatment in both HeLa and A549 cells, which is well-correlated to significant reduction of $\mathrm{H}_{2} \mathrm{O}_{2}$ levels in the cells (Fig. 5B). Taken together, these results strongly suggest that wogonin-induced $\mathrm{H}_{2} \mathrm{O}_{2}$ accumulation substantially contributes to the potentiated cytotoxicity caused by cisplatin and wogonin co-treatment. 

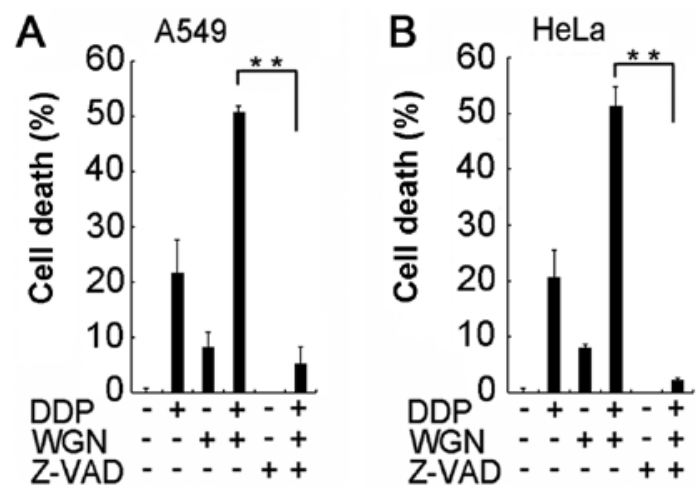

Figure 3. Caspase inhibitor suppresses synergistic cytotoxicity in wogonin and cisplatin co-treated cells. A549 cells (A) and HeLa cells (B) were pretreated with Z-VAD-FMK $(20 \mu \mathrm{M})$ for $30 \mathrm{~min}$ or remained untreated and then treated with $10 \mu \mathrm{M}$ wogonin or $7.5 \mu \mathrm{M}$ cisplatin individually or both for another $72 \mathrm{~h}$. Cell death was measured as described in Fig. 1B. ${ }^{* * *} \mathrm{P}<0.01$.

A

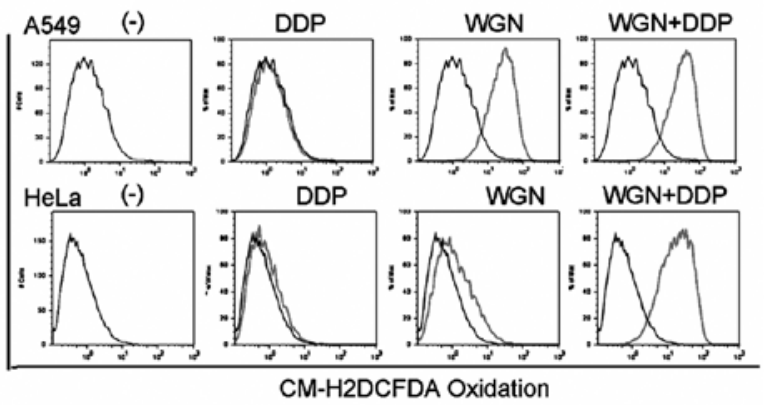

B

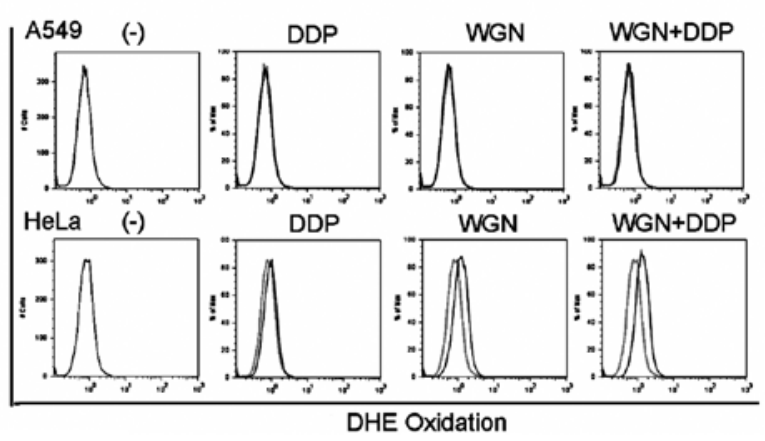

Figure 4. Wogonin induces intracellular $\mathrm{H}_{2} \mathrm{O}_{2}$ accumulation in cancer cells. A549 cells and HeLa cells were treated with $10 \mu \mathrm{M}$ wogonin or $7.5 \mu \mathrm{M}$ cisplatin or both for $60 \mathrm{~min}$. CM-H $\mathrm{H}_{2}$ DCFDA $(5 \mu \mathrm{M})(\mathrm{A})$ or DHE $(5 \mu \mathrm{M})(\mathrm{B})$ was added $30 \mathrm{~min}$ before collecting cells. The fluorescent intensities were analyzed by flow cytometry. Untreated cells with $\mathrm{CM}-\mathrm{H}_{2} \mathrm{DCDA}$ or DHE staining were used as a negative control. The histogram overlays show the results of treated cells (grey lines) compared with untreated cells (dark lines). $\mathrm{x}$-axis, fluorescent intensity showing the extent of CM- $\mathrm{H}_{2} \mathrm{DCFDA}$ or DHE oxidation; $y$-axis, cell number.

\section{Discussion}

In the current study, we demonstrate for the first time that wogonin is able to sensitize cisplatin-induced apoptosis through a ROS-dependent mechanism in the non-small cell lung cancer cell line A549 and the cervical cancer cell line HeLa. First, combination treatment of these two cell lines with wogonin and cisplatin showed synergistic cytotoxicity
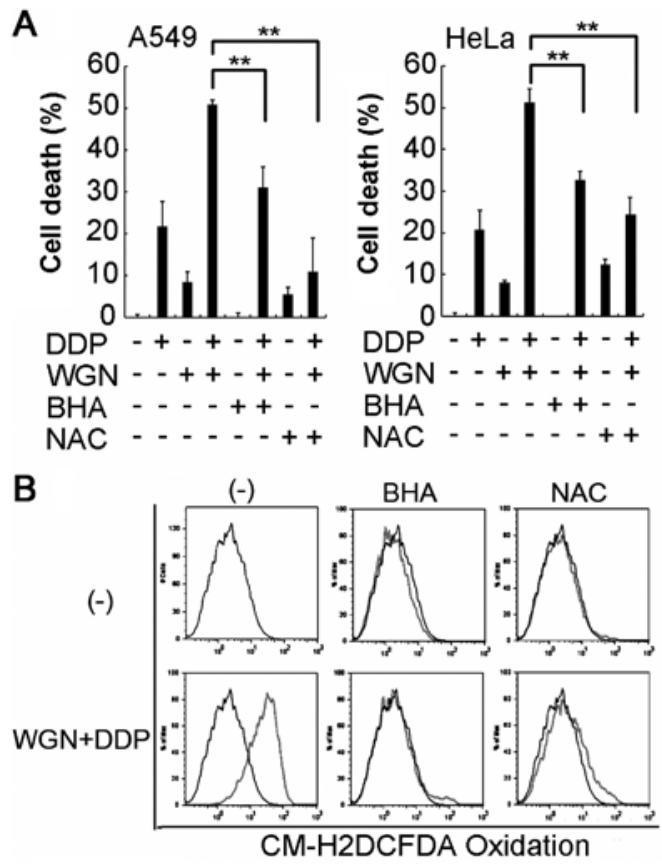

Figure 5. Intracellular $\mathrm{H}_{2} \mathrm{O}_{2}$ accumulation contributes to the synergistic cytotoxicity induced by wogonin plus cisplatin in cancer cells. (A) A549 cells and HeLa cells were pretreated with BHA $(100 \mu \mathrm{M})$ or NAC $(1 \mathrm{mM})$ for $30 \mathrm{~min}$ or remained untreated and then treated with $10 \mu \mathrm{M}$ wogonin or $7.5 \mu \mathrm{M}$ cisplatin or both for $72 \mathrm{~h}$. Cell death was measured as described in Fig. 1B. (B) A549 cells were pretreated with BHA $(100 \mu \mathrm{M})$ or NAC $(1 \mathrm{mM})$ for $30 \mathrm{~min}$ or remained untreated and then cotreated with $10 \mu \mathrm{M}$ wogonin and $7.5 \mu \mathrm{M}$ cisplatin for another $60 \mathrm{~min}$. Cells were stained with CM-H2DCFDA $30 \mathrm{~min}$ before collecting cells and then analyzed by flow cytometer.

in a dose-dependent manner. Second, apoptosis was significantly enhanced in wogonin and cisplatin co-treated cancer cells, which was indicated by the potentiation of activation of caspase- 3 and cleavage of the caspase- 3 substrate PARP in co-treated cells. Third, wogonin robustly induced $\mathrm{H}_{2} \mathrm{O}_{2}$ accumulation in both A549 and HeLa cells and two reactive oxygen species scavengers BHA and NAC significantly suppressed the synergistic cytotoxicity caused by wogonin and cisplatin co-treatment, indicating $\mathrm{H}_{2} \mathrm{O}_{2}$ induced by wogonin substantially contributes to the synergistic cytotoxicity.

Flavonoids are a group of naturally occurring polyphenolic compounds found ubiquitously in plants and abundantly present in human diets. Humans ingest significant quantities of flavonoids in their diet because of their widespread distribution. Scutellaria baicalensis Georgi was widely used as an anti-inflammatory herbal remedy in traditional Chinese and Japanese medicine. In this study, we tested the major flavonoids (wogonin) in Scutellaria baicalensis Georgi and found that it sensitized cisplatin-induced apoptosis through an $\mathrm{H}_{2} \mathrm{O}_{2}$-dependent mechanism. Although flavonoids are most commonly known for their antioxidant activity, previous studies from our group and several other groups have demonstrated that wogonin robustly induced intracellular $\mathrm{H}_{2} \mathrm{O}_{2}$ accumulation in cancer cells, which contributed to the wogonin anticancer activity $(8,12,13,16)$. We also found that wogonin induced $\mathrm{H}_{2} \mathrm{O}_{2}$ through suppression of catalase activity in cancer cells (13). Interestingly, wogonin induces marginal $\mathrm{H}_{2} \mathrm{O}_{2}$ accumulation in normal peripheral T cells and 
immortalized normal bronchial epithelial cells, which may explain the selective cytotoxicity of wogonin on malignant cells. Indeed, the pro-oxidant activity of other flavonoids such as quercetin and luteolin has also been shown by increasing number of reports $(15,17,18)$. It is believed that antioxidant and pro-oxidants behavior of flavonoids may depend on the structure of flavonoids, the source of the free radicals, and the context and microenvironment of the cell such as the presence and concentration of $\mathrm{Fe}$ and $\mathrm{Cu}$ ions $(19,20)$.

The pharmacological mechanisms of cisplatin and etoposide are apparently different. Etoposide prevents re-ligation of the DNA strands by forming a ternary complex with DNA and the topoisomerase II enzyme, thus to cause errors in DNA synthesis and promote apoptosis of cancer cells (21). Cisplatin disrupts DNA function and induces apoptosis by interacting with DNA to form DNA adducts. It is noteworthy that wogonin is able to sensitize cancer cells to apoptosis induced by both etoposide and cisplatin, two widely used frontline chemotherapeutics. Previously, the sensitizing effect of wogonin on etoposide-induced apoptosis in cancer cells was reported to involve inhibition of P-glycoprotein (10). Whereas the results from this study strongly suggest that intracellular $\mathrm{H}_{2} \mathrm{O}_{2}$ accumulation contributes substantially to the enhanced apoptosis observed in wogonin and cisplatin co-treated cancer cells, although other mechanisms are not excluded. ROS are important modulator of cellular signaling and can cause DNA-damage directly. The underlying molecular mechanisms by which wogonin-induced $\mathrm{H}_{2} \mathrm{O}_{2}$ sensitized cisplatin-induced apoptosis are likely multifactorial and worthy further study. One possible mechanism may involve $\mathrm{H}_{2} \mathrm{O}_{2}$ mediated-downregulation of $\mathrm{Bcl}-2$ protein through dephosphorylation and ubiquitination of the protein, which facilitates its degradation by proteasome $(22,23)$. It is also possible that $\mathrm{H}_{2} \mathrm{O}_{2}$ oxidizes important cellular components such as DNA to trigger DNA damage-mediated apoptosis (24). Nevertheless, our results clearly suggest that wogonin could be used as a cisplatin sensitizer for cancer therapy.

\section{Acknowledgements}

This study was supported in part by grant 81172111 from National Natural Science Foundation of China, and also partly supported by grant 2010JQ0012 from the Young Scientist Fund of Science and Technology Department of Sichuan Province, China.

\section{References}

1. Cohen SM and Lippard SJ: Cisplatin: from DNA damage to cancer chemotherapy. Prog Nucleic Acid Res Mol Biol 67: 93-130, 2001

2. Siddik ZH: Cisplatin: mode of cytotoxic action and molecular basis of resistance. Oncogene 22: 7265-7279, 2003.

3. Niedner H, Christen R, Lin X, Kondo A and Howell SB: Identification of genes that mediate sensitivity to cisplatin. Mol Pharmacol 60: 1153-1160, 2001

4. Chi YS, Lim H, Park H and Kim HP: Effects of wogonin, a plant flavone from Scutellaria radix, on skin inflammation: in vivo regulation of inflammation-associated gene expression. Biochem Pharmacol 66: 1271-1278, 2003.

5. Zhao Y, Li H, Gao Z, Gong Y and Xu H: Effects of flavonoids extracted from Scutellaria baicalensis Georgi on hemin-nitrite$\mathrm{H}_{2} \mathrm{O}_{2}$ induced liver injury. Eur J Pharmacol 536: 192-199, 2006.
6. Ma SC, Du J, But PP, Deng XL, Zhang YW, Ooi VE, Xu HX, Lee SH and Lee SF: Antiviral chinese medicinal herbs against respiratory syncytial virus. J Ethnopharmacol 79: 205-211, 2002.

7. Lee DH, Kim C, Zhang L and Lee YJ: Role of p53, PUMA, and Bax in wogonin-induced apoptosis in human cancer cells. Biochem Pharmacol 75: 2020-2033, 2008.

8. Baumann S, Fas SC, Giaisi M, Muller WW, Merling A, Gulow K, Edler L, Krammer PH and Li-Weber M: Wogonin preferentially kills malignant lymphocytes and suppresses T-cell tumor growth by inducing PLC $\gamma 1-$ and $\mathrm{Ca}^{2+}$-dependent apoptosis. Blood 111: 2354-2363, 2008.

9. Enomoto R, Koshiba C, Suzuki C and Lee E: Wogonin potentiates the antitumor action of etoposide and ameliorates its adverse effects. Cancer Chemother Pharmacol 67: 1063-1072, 2011.

10. Lee E, Enomoto R, Koshiba $\mathrm{C}$ and Hirano $\mathrm{H}$ : Inhibition of P-glycoprotein by wogonin is involved with the potentiation of etoposide-induced apoptosis in cancer cells. Ann NY Acad Sci 1171: 132-136, 2009.

11. Wang HW, Lin CP, Chiu JH, Chow KC, Kuo KT, Lin CS and Wang LS: Reversal of inflammation-associated dihydrodiol dehydrogenases (AKR1C1 and AKR1C2) overexpression and drug resistance in non-small cell lung cancer cells by wogonin and chrysin. Int J Cancer 120: 2019-2027, 2007.

12. Lee DH, Rhee JG and Lee YJ: Reactive oxygen species up-regulate p53 and Puma; a possible mechanism for apoptosis during combined treatment with TRAIL and wogonin. Br J Pharmacol 157: 1189-1202, 2009.

13. Yang L, Zheng XL, Sun H, Zhong YJ, Wang Q, He HN, Shi XW, Zhou B, Li JK, Lin Y, et al: Catalase suppression-mediated $\mathrm{H}(2) \mathrm{O}(2)$ accumulation in cancer cells by wogonin effectively blocks tumor necrosis factor-induced $\mathrm{NF}-\kappa \mathrm{B}$ activation and sensitizes apoptosis. Cancer Sci 102: 870-876.

14. Wang X, Ju W, Renouard J, Aden J, Belinsky SA and Lin Y: 17-Allylamino-17-demethoxygeldanamycin synergistically potentiates tumor necrosis factor-induced lung cancer cell death by blocking the nuclear factor- $\kappa \mathrm{B}$ pathway. Cancer Res 66: 1089-1095, 2006.

15. Ju W, Wang X, Shi H, Chen W, Belinsky SA and Lin Y: A critical role of luteolin-induced reactive oxygen species in blockage of tumor necrosis factor-activated nuclear factor- $\kappa \mathrm{B}$ pathway and sensitization of apoptosis in lung cancer cells. Mol Pharmacol 71: 1381-1388, 2007.

16. Fas SC, Baumann S, Zhu JY, Giaisi M, Treiber MK, Mahlknecht U, Krammer PH and Li-Weber M: Wogonin sensitizes resistant malignant cells to TNF $\alpha$ - and TRAIL-induced apoptosis. Blood 108: 3700-3706, 2006

17. Galati G and O'Brien PJ: Potential toxicity of flavonoids and other dietary phenolics: significance for their chemopreventive and anticancer properties. Free Radic Biol Med 37: 287-303, 2004.

18. Lin Y, Shi R, Wang X and Shen HM: Luteolin, a flavonoid with potential for cancer prevention and therapy. Curr Cancer Drug Targets 8: 634-646, 2008.

19. Cao G, Sofic E and Prior RL: Antioxidant and prooxidant behavior of flavonoids: structure-activity relationships. Free Radic Biol Med 22: 749-760, 1997.

20. Sugihara N, Arakawa T, Ohnishi M and Furuno K: Anti- and pro-oxidative effects of flavonoids on metal-induced lipid hydroperoxide-dependent lipid peroxidation in cultured hepatocytes loaded with $\alpha$-linolenic acid. Free Radic Biol Med 27: 1313-1323, 1999.

21. Gordaliza M, Garcia PA, del Corral JM, Castro MA and GomezZurita MA: Podophyllotoxin: distribution, sources, applications and new cytotoxic derivatives. Toxicon 44: 441-459, 2004.

22. Hildeman DA, Mitchell T, Aronow B, Wojciechowski S, Kappler J and Marrack P: Control of Bcl-2 expression by reactive oxygen species. Proc Natl Acad Sci USA 100: 15035-15040, 2003.

23. Wang L, Chanvorachote P, Toledo D, Stehlik C, Mercer RR, Castranova V and Rojanasakul Y: Peroxide is a key mediator of Bcl-2 down-regulation and apoptosis induction by cisplatin in human lung cancer cells. Mol Pharmacol 73: 119-127, 2008.

24. Tenopoulou M, Doulias PT, Barbouti A, Brunk U and Galaris D: Role of compartmentalized redox-active iron in hydrogen peroxide-induced DNA damage and apoptosis. Biochem J 387: 703-710, 2005. 